\title{
Social and Cognitive Implications of Using Euphemisms in English
}

\author{
Narmina Fataliyeva Arif ${ }^{1}$ \\ ${ }^{1}$ Narmina Fataliyeva Arif, Department of English language and Literature, Khazar University, Baku, Azerbaijan \\ Correspondence: Narmina Fataliyeva Arif, Department of English language and Literature, Khazar University, \\ Baku, Azerbaijan. E-mail: narmina.fataliyeva@mail.ru
}

$\begin{aligned} & \text { Received: September 29, } 2015 \\ & \text { Accepted: November 8, } 2015 \quad \text { Online Published: November 30, } 2015 \\ & \text { doi:10.5539/ijel.v5n6p151 }\end{aligned}$ URL: http://dx.doi.org/10.5539/ijel.v5n6p151

\begin{abstract}
Today in a globalized society the need for word substitutions while speaking on sensitive topics has increased. People search for milder alternatives to express their opinions whenever they feel their words might sound abrupt or offensive. These substitutions are called euphemisms.

At first sight one might suppose that these expressions are too ordinary, but in fact they possess a strong persuasive character. Thus, the subject of this article is to identify the main functions of euphemisms in modern society. The article also aims at determining which social and cognitive factors regulate our choice of these substitutions.

In the theoretical part of the research different views on the phenomenon are outlined.

The main method used in this work is descriptive analytical method, based on the description of euphemisms from theoretical point of view with the subsequent analysis of achieved results. Besides, the method of contextual analysis has been applied.

As data for analysis different euphemistic expressions have been studied.

An overall study shows that in modern life honest debate has turned into a rare phenomenon.

One of our assertions is that the use of euphemisms primarily presupposing good intentions so as not to hurt a listener's feelings, in modern life has acquired completely a different purpose. Today people use euphemisms to sound more persuasive instead of simply sounding polite.

It should be noted that for a deeper understanding of the role of euphemisms they should be studied within a specific discourse. Thus this study will require a further look at the problem applying a more contextual approach to its analysis.
\end{abstract}

Keywords: euphemisms, choice of euphemisms, social implications, cognitive implications, public opinion, political speech, political correctness, discourse, doublespeak

\section{Introduction}

Human nature has a tendency to avoid naming things, objects or phenomena directly. During communication speakers try to minimize the potentially offensive effect of expressions they use. They avoid mentioning any expression that might disturb the harmony of the conversation. In order to replace the original signifier that may be perceived as offensive or unpleasant, people use euphemisms, i.e., words which are used to soften the potentially negative impact of the expression. William Lutz was absolutely right in saying that "language is designed to evade responsibility, make the unpleasant appear pleasant, the unattractive appear attractive". (Lutz, 1987)

It is obvious that originally words named exactly the same things and objects they meant to. However, throughout the development of society, people started to fear mentioning evil spirits as they believed that "words possessed immense power" and therefore might attract bad luck. In this regard Brno stresses, "attempts to use euphemisms are as old as our ability to use language." (Brno, 2012)

Thus the first euphemisms were said to be more religious in character because they described religious events and were related to social aspects of people's lives. Even in a modern society people in some cultures have superstitious beliefs that words are capable of attracting something negative. For example, "cancer" might sound to some people spiritually imperiling, so they avoid mentioning it. 
Taking all this into consideration, many linguists link the phenomenon of taboo to euphemisms. Taboo emerged as a result of prohibition of doing certain activities and, according, discussion of forbidden topics. People face difficulties in making a choice simply because they need to decide what is good and what is bad about a definite statement. Hence, taboo itself is an eventual product of individual's thinking ability. Accordingly, some linguists see the source of taboos in prejudice and deny the existence of "genetic ties" between modern euphemisms and taboo. On this account such euphemisms have been named by linguists as superstitious.

Thus, the first euphemisms are considered to be social in nature, since they were created by people in order to talk about topics related to their social life, in particular to areas such as death, religion and so on.

A high level of education and the development of society have made a great contribution to seeking acceptable ways of speaking on almost every topic. Today in globalized society there is no topic which is forbidden; no topic which is unspeakable.

Apparently, the meaning of euphemisms appears to be murky for "they do not form complete pictures in the mind" (Mihas, 2005) This is true, since we behave in accordance with the norms invented by society speaking on taboo topics. Ignoring people's beliefs about certain phenomena may result in serious misunderstandings between speakers.

\section{Different Views on Euphemisms}

Euphemization is one of the most intensive tendencies in linguistics. Therefore, it is not surprising that in literature there are numerous research works devoted to it. Euphemism is a linguistic device which draws linguists' attention again and again and it still remains one of the central problems in Modern English.

Alkaire thinks that euphemisms have Latin roots and most of them came into the language after the Norman Conquest of England in 1066, when Latin was the main language of the ruling classes and the aristocracy (Alkire, 2002). However, according to Enright the term "euphemism" comes from the Greek language and it means "to talk in a correct way" (Enright, 2004). Similarly, Online Etymology Dictionary states that it is originally a Greek word with two parts, viz. "eu", which means "good", and "pheme", which means "speaking" (Online Etymology Dictionary, 2012).

Euphemisms have been defined by linguists differently. Most linguists take ethic norms of behavior into consideration while speaking about the reasons why euphemisms emerge in language. Allan and Burridge, for instance, refer to euphemisms as "deodorizing spray and perfume" (Allan \& Burridge, 1991).

William Lutz focuses on ethical considerations as well and calls the euphemism "the morality of rhetoric." (Lutz, 1987) Crespo Fernández emphasizes the importance of euphemisms in everyday speech and treats them as a form of "verbal behavior" (Fernández, 2005).

Fairclough also considers "euphemism as an everyday, comprehensive phenomenon, which serves a specific, functional purpose in social discourse" (Fairclough, 2008).

Meanwhile, there are linguists who treat euphemisms as a source of deception. In this connection, Lacone thinks that euphemisms can "hide seemingly simple and straightforward words behind deceptive or overly complex ones" (Lacone, 2003).

Elena Mihas indicates "euphemizing, undoubtedly, serves as a linguistic bridge to indirectness that tends to dominate human communication in the modern era" (Mihas, 2005).

LaRocque (2006) even enhances this opinion, emphasizing that "euphemisms which deal with political, military and commercial concepts can be particularly deceptive and controversial".

The same point of view is supported by Safire (2008). He focuses on the importance of euphemisms related to environmental issues. He states that alongside political, business and military issues environmental problems have led to the birth of many euphemisms, many of which are misleading and highly debatable.

\subsection{Need for Euphemization in English}

From the definitions above it becomes clear that the reasons why words are euphemized are different.

Bearing these points in mind, it is important to look at factors, on basis of which the need for euphemistic expressions arises.

Firstly, each time we convey a piece of information we deliberately try to pay attention to the choice of words. In literary texts, for example, euphemisms are used to serve the following functions: make the language sound more literary, create a humoristic effect in the message, characterize personages and create more vivid images. But these are purely linguistic factors of the use of euphemisms. 
Secondly, when people appeal to euphemisms and try to avoid the direct naming of unpleasant things, they want to sound polite and tactful and sometimes more official. This desire is enhanced especially when we want the listener to believe us, we want to shape a sense of right and wrong in him, we want to influence his view of world. Therefore, there are extra linguistic factors governing our choice of euphemistic expressions, that is, they are related to reality.

Hence, euphemisms are an unstable phenomenon of a language emergence of which depends on different historical periods, social and economic welfare and the psychological state of the speaker.

Studying the intricate nature of euphemisms Laura Samoškaite focuses on social and cognitive factors. In this connection Laura Samoškaite states that "the need for euphemisms is both social and emotional, as it allows discussion of "touchy" or taboo subjects (such as sex, personal appearances, or religion) without enraging, outraging, or upsetting other people." (Samoškaite)

We also use euphemisms as strong instruments to influence and sometimes to manipulate the listener or alter his or her perception of actual facts. There are a lot of such misleading words in public speeches, official papers, media, etc. For example, euphemism in advertisement bear an inducing function. Some airline companies have divided the grades of passenger compartments into four ranks. Instead of "first class" they use "deluxe" or "premium class". The "second class" is transformed into "first class" whereas the "third class" is revised as "business class" or "tourist class". (Samoškaitè)

R. De Beaugrande stresses that euphemisms used in modern culture help "to conceal something pejorative behind a softened or manipulated expression" (De Beaugrande).

\section{Factors Influencing the Formation of Euphemisms}

Among the factors affecting the formation of euphemisms, the most essential ones are regional emergence, culture of the area, its customs and traditions, specific location, etc.

For example, in English for the expression "go to the toilet" there are various synonymous expressions such as "go to the loo", "to visit Lady Periam", etc. If we look closer at them we can see that the latter is more euphemistic in nature and sounds a bit peculiar.

Students in Balliol College of Oxford University, for instance, instead of "go to toilet" frequently use a euphemistic expression "visit Lady Periam" just because this college toilets were built on lands donated by Lady Periam. It is obvious, then, that such a choice being made during the conversation might not be understood by everyone who lives in the UK, simply because it has a very narrow, specific usage. In the south of England, for example, another expression "spend a penny" is used which also means "go to the toilet". So, its creation definitely involves a regional cultural factor and this euphemism will not be perceived by all Englishmen in the same way.

Similarly, a death caused by the sea is usually associated with a tide and in English there is a corresponding euphemism for that, "go with the tide". Besides, in American English for describing death such synonymous expressions as "go over the range" or "cross the Great Divide" can also be found. (Www.eng.hi138.com).These euphemisms owe their emergence to a particular location, namely the mountainous area in the west of America, where they are used. So, the geographic environment has a great influence on the formation of various euphemisms too.

\section{Euphemisms and Doublespeak}

Speaking about the intricate nature of euphemisms it is almost impossible not to touch upon the concept of Doublespeak established by William Lutz. He states, "when a euphemism is used to mislead or deceive it becomes doublespeak". He defines doublespeak as "language that avoids or shifts responsibility, language that is at variance with its real or purported meaning. It is language that conceals or prevents thought; rather than extending thought, doublespeak limits it" (Lutz, 1987).

Today if we take a look at any official paper or listen to a speech of any political representative we can see how much truth was in his words. Elena Mihas notes, "I believe the concept of language as mediation is a key to understanding the nature of political discourse" (Mihas, 2005).

Doublespeak is almost the language of today's politics, economy, medicine and social life in general. We can feel its presence in almost every sphere of our life.

In 1990s this intention to select the correct words to speak on political issues or to conceal unsuccessful actions or illegal operations acquired the name political correctness. By using "politically correct words" leaders try to convince people of their good intentions. 


\section{Political discourse and Euphemisms}

As we can see from the discussion above, Doublespeak and euphemism are closely interconnected phenomena. The existence of one is nearly impossible without the other.

Monika Ibi stresses that many such continually repeated catchy euphemisms have entered the political lexicon and "have their roots in the purposeful concealment of facts from the outside world".

Today in our globalized society the following spheres of human activity can be considered to be mostly penetrated with euphemisms: politics, economics, business, medicine, mass media, etc.

One of the distinct features of politics as compared to other areas of human activity is its discursive character.

A political action is sometimes merely equal to official speech. Moreover, language and politics are so interconnected that political activity is also occasionally treated as a kind of language activity.

Hence, only studying euphemisms within a frame of contextual reality can reveal the richness of their functions.

According to Poskachina "organization and transfer of information in the political discourse is directly related to the selection of the necessary linguistic unit or several units from a synonymous row that might affect the entire meaning of the discourse." (Poskachina, 2010) As euphemisms are considered to be one form of synonymy, this opinion can refer to them as well.

According to Zaychikova three basic characteristics of discourse are worth mentioning: 1) discourse is fixed in text, 2) it has a cognitive foundation, 3) it is ideologically marked. Zaychikova indicates that these characteristics of discourse are fundamental to the analysis of any type of discourse (Zaychikova, 2003).

Moreover, most linguists indicate that among various discourse types literary, political, and media discourses are of special interest because "they are strongly pragmatically, cognitively, ideologically and culturally motivated." (Mammadov, 2015) He continues, "various rhetorical strategies of explicit grammatical, lexical, and stylistic devices (conjunctions, pronouns, articles, word order, repetitions, metonymy, metaphor, the names of person, place, literature, brand names, etc.) are creatively and widely used within political discourse to arouse more attention in the receiver, by using cognitive, poetic and other literary effects to perform diverse communicative functions (Mammadov, 2010).

\subsection{Social and Cognitive Implications of Using Euphemisms in Politics and Media}

It is a curious fact that when people are asked when they employed euphemisms in their speech for the last time they are occasionally caught by surprise. Despite a great number of speakers admitting using euphemisms in their speech, they say that they do it unconsciously. This could be true as it has become clear that the need for these substitutions varies from one person to another. Now we are going to look at social and psychological factors more closely. As we know there is a close relationship between language and society and changes that happen in society will, doubtlessly, be reflected in language. Today by studying euphemisms one can get a great amount of information about society and its values. Politics and mass media are major fields where the impact of euphemisms can be perceived more strongly.

Euphemisms are widely applied by politicians with the intention "to attain political correctness or instead of pronouncing unpleasant facts". (Galperin, 1977).

In modern political culture it is easy to alter the public perception of inconvenient truths.

It should be noted that political euphemisms are more formal and stable than euphemisms used in other spheres. Moreover, other spheres of public life appear to be less affected by euphemisms.

Thus politicians build their speeches in accordance with the ideological and cultural preferences of their audience. This is how they hope to obtain a positive response from the listener. Politicians are very skillful at making use of the vague nature of euphemisms to cover up real facts either some criminal acts or to make the politics and economy of the country seem steadier.

However, the other group of linguists think that the use of euphemisms in political science has the purpose to deceive people. Such an expression as raising taxes in today's politics is frequently replaced by euphemisms such as revenue raise or progressive taxation, nuclear weapons are often replaced by special weapons, investment is heard instead of government spending.

Undoubtedly, media plays a huge role in manipulating public opinion. Euphemisms in media help to correct errors made by politicians, monitor their words and statements and thus reshape public opinion about politicians' personalities. 
There is a popular term "spin" used in media as a synonym for euphemism. During the presidential elections in 2004 numerous spins were in use "to publicly defend or downplay errors made by their candidate." (Mihas, 2005) William Safire, a reporter for the New York Times described spins as "deliberate shading of news perception."According to Linda Wertheimer, in National Public Radio, spins are defined as "not quite lying," "not quite truth." Unfortunately, today such expressions as "good life, good death" or "death with dignity" are the most prominent phrases used in media and many suicides are described by means of such euphemisms. In this regard, Wesley J. indicates "euphemisms are a propagandistic tool of misdirection. They ill serve a free people. But advocates won't stop manipulating us until we insist that they, in Humphry's words, "call a spade a spade".

Wesley J. Smith then continues, "the media favor by the words and terms reporters deploy in stories to describe the political combatants." Elena Mihas notes, that "though euphemizing is now an accepted and established practice, it has acquired a dubious connotation in light of its tendency to deliberately disguise actual meanings of words in political discourse." (Mihas, 2005) By using euphemisms political leaders can successfully control the information conveyed. Euphemisms influence people's thoughts concerning social life in such a way that they become misled by the cheating function of euphemisms. For this end Wesley J. Smith states "advocates on all sides of political and cultural spectrums cynically manipulate public opinion through focus group-tested obfuscating words and phrases rather than persuade through candid and accurate descriptions of advocacy agendas."

At the same time, the penetration of rude expressions in everyday speech has become rather perceptible nowadays. Occasionally, using abrupt words and direct expressions is now viewed as a norm in media. Thereby euphemism used in mass media tends to hide information rather than as a means of sounding polite. Its main purpose is to cover up the cruel reality in a complex communication environment.

\section{Conclusion}

It becomes clear that even decent words may undergo euphemistic substitutions just because the speaker feels that the expressions he or she uses may offend the listener.

The discussion above shows that in modern society the initial role of euphemisms has been strongly modified.

It can easily be perceived that the need for euphemistic replacement as a means of politeness is gradually fading, and instead, the need for euphemizing as a means of veiling the cruel reality of modern life is increasing.

Consequently, as long as poverty, wars and economic instability exist in society euphemisms will always survive in language as one of possible ways to meet the requirements of political leaders to cover up their criminal acts and make life seem more politically, economically and socially stable.

\section{References}

Alkire, S. (2002). Introducing Euphemisms to Language Learners. The Internet TESL Journal.

Allan, K., \& Burridge, K. (1991). Euphemism and Dysphemism: language used as shield and weapon. Oxford, OUP.

Brno. (2012). Euphemisms.

De Beaugrande, R. (n.d.). Figures of speech. Retrieved from http://www.beaugrande.bizland.com

Enright, D. (2004). In Other Words. London: Michael O'Mara Books Limited.

Fairclough, N. (1992). Discourse and Social Change. Cambridge \& Malden: Polity Press.

Fernбndez, E. C. (2005). Euphemistic strategies in politeness and face concerns.

Galperin, I. R. (1977). English stylistics. M., Vishshaya shkola.

Ibi, M. (n.d.). Euphemism in Politics. Retrieved from http://www.ibi-academia.com/euphemism-in-politics/

Lacone, S. (2003). Write to the Point: How to Communicate in Business With Style and Purpose. The United States of America: Career Press.

LaRocque, P. (2000). Championship Writing: 450 Ways to Improve Your Writing. The United States of America: Marion Street Press, Inc.

Lutz, W. (1987). Doublespeak at large. English Today, 12, 21-24. http://dx.doi.org/10.1017/S0266078400003072

Lutz, W. (1999). Doublespeak Defined: Cut through the Bull**** and Get the Point! New York: Harper Collins. Mammadov, A. (2010). Metaphors in the American and Russian political discourse. 
Mihas, E. (2005). Non-Literal Language in Political Discourse. University of Wisconsin-Milwaukee.

Poskachina, I. N. (2010). Synonymy as one of the ways of modeling political discourse. Синонимия Vestnik Irkutsk State university of linguistics, 2, 143-149.

Safire, W. (2008). Safire's Political Dictionary. The United Kingdom: Oxford University Press.

Samoškaitè, L. (2011). 21st century political euphemisms in English newspapers: semantic and structural study, Vilnius.

Smith, W. J. (n.d.). Euphemisms as Political Manipulation. Retrieved from http://www.orthodoxytoday.org/view

Transcript of President Obama's Election Night Speech. Retrieved from http://www.nytimes.com

Zaychikova, N. V. (2003). Political Text-Political Discourse-Political Novel. Articles of the first English International association of English teachers. 25-26 November, MSLU. Moscow.

www.etymonline.com/index.php?term=euphemism

www.eng.hi138.com

\section{Copyrights}

Copyright for this article is retained by the author(s), with first publication rights granted to the journal.

This is an open-access article distributed under the terms and conditions of the Creative Commons Attribution license (http://creativecommons.org/licenses/by/3.0/). 